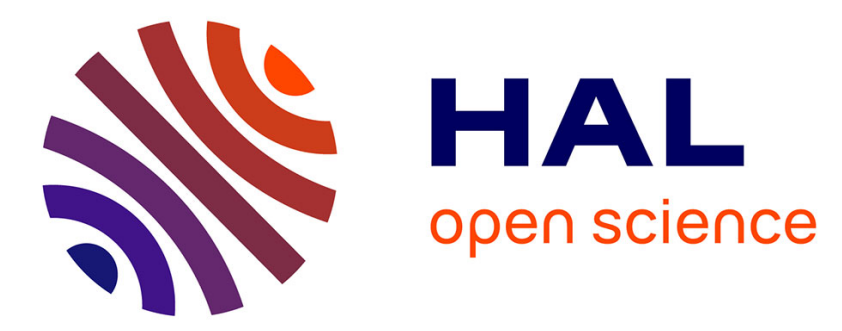

\title{
The 'Global' versus the 'Local': Cognitive processes of kin determination in Aboriginal Australia
}

\author{
Laurent Dousset
}

\section{To cite this version:}

Laurent Dousset. The 'Global' versus the 'Local': Cognitive processes of kin determination in Aboriginal Australia. Oceania, 2008, 78 (3), pp.260-279. hal-00349881

\section{HAL Id: hal-00349881 \\ https://hal.science/hal-00349881}

Submitted on 13 Sep 2015

HAL is a multi-disciplinary open access archive for the deposit and dissemination of scientific research documents, whether they are published or not. The documents may come from teaching and research institutions in France or abroad, or from public or private research centers.
L'archive ouverte pluridisciplinaire HAL, est destinée au dépôt et à la diffusion de documents scientifiques de niveau recherche, publiés ou non, émanant des établissements d'enseignement et de recherche français ou étrangers, des laboratoires publics ou privés.

\section{(1) (1) $\$$}

Distributed under a Creative Commons Attribution - NonCommercial - NoDerivatives| 4.0 


\title{
The 'Global' versus the 'Local': Cognitive Processes of Kin Determination in Aboriginal Australia
}

\author{
Laurent Dousset \\ Centre de Recherches et de Documentation sur l'Océanie (CREDO) \\ Ecole des Hautes Etudes en Sciences Sociales (EHESS)
}

\begin{abstract}
Morgan and his informants' interpretation of Australian social categories as 'marriage classes' has survived in Dumont's (and Viveiros de Castro's) distinction of a 'local' (Dravidian systems) and a 'global' (Australian systems) formula. This paper explains that the 'global formula' is neither a necessary nor an applied device in Australian kin category determination, even when genealogical memory is short and when there is a non-limitation of range in the extension of categories. Instead, a heuristic model, which is called the relational triangle, is proposed. This model depicts the procedure through which Australian people pragmatically determine and extend kin categories. Moreover, it also offers a visualisation of the cognitive schema and processes framing discourse and behaviour in relation to kinship and draws some parallels with Greenberg's hypotheses on markedness in kinship classes.

Key words: Australia, Aborigines, cognitive anthropology, kinship, markedness
\end{abstract}

It is common sense that the advancement of science is cumulative, that each generation builds upon the findings of previous ones, and that revealed mistakes are revised rather than repeated. This, however, is common sense; and common sense does not necessarily have to be what is most widespread. Indeed, there seem to be some questions related to the study of kinship, and in particular Australian kinship, that do not appear to follow the general pattern of cumulative advancement of knowledge. That some believe the study of kinship is dominated by an ethnocentric extrapolation of the Euro-American mode of reckoning relationships, or that it is an error altogether, is one thing. That others, however, depict some particular, but in the end quite important, aspects of kinship as if there had not been any consensus or even progress over the last 50 years, is a matter for great concern.

Among these aspects there is one 1 am concerned with in this paper and that was the subject of lengthy debates, decades ago, but that for some thinkers seems to have remained within the nebula of worthwhile studying and writing. Let us consider this subject once again and, hopefully, terminate it and return to the cumulative process anthropological knowledge supposedly follows. The subject that had been a problem at some stage in the evolution of kinship studies, that seemed to have been resolved, but that re-emerged as an old-new question can be formulated in two ways. One is simple, straightforward and resolved: social category systems in Australia, among them sections and subsections, have to be distinguished from systems of kin classification. The last 30 and more years of research in the domain of kinship in Australia have been breaking away from the former structuralist and structuro-functionalist approaches that saw in sections and subsections the crystalline beauty of Australian kinship and marriage, to paraphrase Lévi-Strauss. 
The second way to formulate the problem follows a more distinguished but also obscure construction, and is interestingly elaborated by non-Australianists such as Viveiros de Castro (1998). It is this construction this paper is concerned with. What is really at stake in this second approach is the hypothesis that what are summarised under the notion of 'global' social categories (sections and subsections) are seen as necessary devices in the recognition of kin. Viveiros de Castro and others claim that these 'global' social categories are in every case latently or covertly the necessary mealis through which people's kin categories are determined in Aboriginal Australia. The 'global' refers here to Dumont's (1983, 1997 [1971]) mode of characterising Kariera-like (Australian) kinship and section systems, while its opposite, the 'local', stands for Dravidian-type systems which lack social category systems. In the context of shallow genealogical memory, these global categories are thought to function as devices that pragmatically allow people to determine in which kin category they stand in relation to each other. As such, sections and subsections are considered devices inherent in systems of kin classification. Australianists, on the other hand, agree that these global categories are not needed in everyday processes of kin classification.

As already foreshadowed, in this paper I shall enter once again into a debate that to a certain extent has accompanied Australian anthropology since its early years, that has disappeared from the scientific arena, but that is re-emerging in non-Australianist writings. After a brief discussion of some of the most basic features of Dravidian ('local') and Australian ('global') systems, I shall argue that sections, which are the principal devices inherent in Dumont's and Viveiros de Castro's 'global' formula, neither reproduce terminological structure nor act as mechanisms involved in pragmatic kin-recognition. Since the illustration of pragmatic kin-recognition cannot easily be generalised, I will use a particular example from the Australian Western Desert.

As an alternative model to the 'global' formula, and as an answer to those who highlight its necessity in the Australian context, this paper will propose a straightforward schematisation of some of the cognitive processes at work in kin category determination. These processes proceed by way of what 1 call the relational triangle, a device inherent in everyday interaction and discourse, as well as being a model reproducing Indigenous peoples' mode of conceptualising relations via the idiom of kinship. As we will see, this model is strongly correlated to Greenberg's hypotheses on the universal features of kin terminologies, which he associated with the factor of markedness: the categories that are contained within the application of the relational triangle are those that Greenberg would classify as being unmarked, while marked categories are avoided. A second theoretical issue relates to the congruency between d'Andrade's (2000) depiction of cognitive schemes as 'simplified worlds' and Greenberg's (1990 [1980]) hypotheses just mentioned. I will endeavour to show that the categories constituting the paradigmatic choices which can be depicted as being unmarked constitute a 'simplified world'. Both the idea of the simplified world and its congruency with the unmarked characteristic show that cognition seems, even in the domain of kinship, to be heavily based on a principle of economy, reflecting the need to order and organise a complex world by eliminating or resolving redundancies, contradictions and indirect relationships.

\section{THE LOCAL AND THE GLOBAL FORMULAE}

Many of the better known current theoretical writings mentioning Aboriginal Australian kinship predominantly refer to the ethnographies of Radcliffe-Brown and Elkin, and have lately been summarising the various Aboriginal kinship systems under the heading 'Australian', usually associated with Kariera-type systems, and 'Normal Australian', somehow based on the Aranda-type (see Godelier et al. 1998). ${ }^{2}$ With some exceptions, such as the Murngin type (Yolngu of Arnhem Land) and the Aluridja type of the Western Desert, both usually dismissed as anomalous or at least unexpected and complex (see Dousset 2002, 2003), there is only rarely 
any reference to Dieri, Karadjeri or other types, or to skewing, although the latter is widely found alongside other types of classifications throughout large areas of Australia, especially in northein Queensland (e.g. McConvell \& Alpher 2002; Powell 2002).

Moreover, the 'Australian' and 'Normal Australian' types are defined and illustrated in ways that correspond only with difficulty to the ethnographic material. These ideal-types of formally determined kinship models elaborate on a minimal set of features and terms, neglecting the pragmatic usage of the sistem and the structural variations and nuances these usages involve. As we shall see below, these theoretical approaches seem to have remained blocked at an analytical level that conflates social category systems, such as sections and sub-sections, and the interrelational and egocentric kinship terminology. Such analyses, which disregard many more social processes than they include, are hardly appropriate in current Australian anthropological practice, where research undertaken for Native Title purposes has considerably accentuated the need for detailed ethnographies and comprehensive explanatory models (see Sutton 1998).

Although the above-mentioned 'global' approach has constantly recurred throughout Australian ethnology - starting with Morgan's 'marriage classes' - it finds its modern roots in some of Lévi-Strauss' writings, which were later considerably reinforced by Dumont. As Viveiros de Castro explains (1998), it was Radcliffe-Brown (1953) who, in response to Dumont (1953), defined an Australian-Dravidian type of kinship system, with which-in reference to the Kariera (Radcliffe-Brown 1913) - he associated bilateral cross-cousin marriage and a conflation of the affinal and the consanguinal terminology. Dravidian and Kariera-type systems would usually not need a specific set of affinal terms, for cross relatives are automatically or mechanically affines as well.

Dumont (1983, 1997 [1971]), however, wanted the distinction between Indian-Dravidian and Australian-Kariera underlined and maintained; and he did so by introducing the concepts of the 'local' and the 'global' formulae, the former corresponding to Indian Dravidian types, the latter to the Australian type. There is an important difference marking Australian and Dravidian systems, explains Dumont (1997 [1971]:149 note 1), which reflects a difference in the presence or absence of a global system of intermarriage, a notion that is ultimately not significantly distinct from what was previously termed the consequence and function of 'marriage classes' (see Dumont 1997:119).

Viveiros de Castro, notably an 'Americanist' albeit with widespread theoretical interests, perpetuates Dumont's legacy and writes that:

The basic Australian terminological type is consistent with a sociocentric bipartition or quadripartition-that is, a logical consistency, not mutual implication or sociological causation (1998:339; see also pp 333, 370).

By way of an elegant detour through Scheffler's claim that section systems are reifications of terminological superclasses, Viveiros de Castro (1998:339) reiterates a claim that had been abandoned in Australia since Radcliffe-Brown: 'such reifications do imply that the terminology is organised according to principles formally equivalent to a sociocentric calculus of marriage "classes"".

Like Dumont, Viveiros de Castro adds other characteristics distinguishing Dravidian and Australian systems, supposedly justifying the definition of the 'global' and the 'local' formulae. For example, while both terminological systems express marriage alliance relations (and in Dumont's words, 'marriage alliance' is what Lévi-Strauss termed 'direct exchange'), they differ from each other in the mode of classifying relatives in $\mathrm{G} \pm 2$ :

$[T]$ he neutralization of the consanguine/affine opposition in these generations, in the Dravidian case, reveals a linear generational time and an ego-centered vision of alliance, whereas the maintaining of the opposition and of the autoreciprocity of 
the terms in $\mathrm{G} \pm 2$ (i.e., same terms for grandparents and grandchildren) in the Kariera case expresses a circular conception of time and a collective sociocentric intermarriage relation between the terminological 'moieties' (Viveiros de Castro 1998:336).

As Shapiro (1970:385) explained, and as Viveiros de Castro reiterates himself in the paper quoted above, the autoreciprocity in $\mathrm{G} \pm 2$ is sociologically rather trivial. Moreover, it could be argued that the circular conception of time is not necessarily grounded on, or linked to, the 'global' formula. Pitjantjatjara-speaking people in the Northern Territory and in north-western South Australia, for example, have auto- or self-reciprocal terms, but no sections or subsections. Dumont also includes aspects of lineality in the discussion of Dravidian and Australian systems. I shall not, however, further elaborate these theoretical propositions, as kin classification terminology-be it with or without specific affinal setsand marriage prescription, whether jural (Leach 1965) or structural (Needham 1973), have no direct influences on ethnographically recognisable principles of lineality in Australia.

The terminological auto-reciprocity and circular conception of kinship time are, I believe, characteristics used to reinforce, albeit unconvincingly, Dumont's distinction of the global and the local formulae as based on the existence or absence of social category systems, especially in a society which has an unlimited range for the extension of kin categories, as we shall see below. In this paper, 1 argue that neither this extension, nor the determination of the cross-parallel distinction necessitates the existence of global categories. I claim that not only is there no need for a global formula, but also that, where such a system is known, it is not always a device which is pragmatically applied in the determination of kin categories. In this sense, Scheffler's (and Lounsbury's) assumption and findings that kinship terms constitute a genealogically predicated field (see Hirschfeld 1986:218), which eradicates the need for a global formula in kin recognition as well as in marriage prescription, are confirmed. On the other hand, I argue that interpreting extension of kin categories solely as a metaphor of genealogically close relationships neglects the pragmatic and cognitive mechanisms that are at work. Extension proceeds by way of a structural and cognitive process I call the relational triangle, a process that reflects the Indigenous principles underlying their representation, as well as their portrayal of kinship.

\section{COGNITIVE SCIENCES AND THE STUDY OF KINSHIP}

The expression 'cognitive processes', as used in this paper, relates to the verbal and mental/structural-as verbally illustrated-mechanisms that are involved in kin category recognition and determination. The approach embraced and the material presented, however, have to be to some extent distinguished from some of the better known 'cognitive' approaches applied to kinship, some of which I have already alluded to above.

Best represented in this respect are Lounsbury (e.g. 1956, 1964) and Goodenough's (1968 [1956]) componential analyses, an approach that was Jater applied to Aboriginal Australian kinship systems by Scheffler $(1971,1972,1978)$. Componential or semantic analysis, as it was also termed, emerged from the ethnosciences or ethnosemantics with the aim of studying 'the thought systems of individuals in other cultures and sometimes in our own' (Gardner 1987 [1985]:244). Attracted by the methodological and theoretical rigour deve]oped in linguistics, computer simulation and information theory, anthropologists developed ways to approach social phenomena in a similar fashion. Kinship, often implicitly interpreted as an independent social domain with a limited set of terms or categories and explicit structural interrelations, presented jtself as an ideal type or ideal test case for such newly developed methodologies. As McKellin (1995:20) writes, 'kin terms and other cultural representations were thought to exhibit the same properties as other systems of rule-governed semiotic codes'. Among these, McKellin explains further, were the assumptions that sym- 
bols are qualitatively distinct, that they are governed by logical rules, that they are shared by their users, and that they are essentially context-free. Hence, to translate this into an example, the English word 'Mother' is such a symbol, as it is distinguished from other terms such as 'Father'; it involves an unambiguous genealogical connection; and covers, with respect to this genealogical connection the same semantic field for all users of a given cultural background-in this case Euro-American-independently of the context of its use. Kinship systems, and more specifical!y their terminologies, seemed to reflect and to be structured by such unambiguous semióric codes.

Terminologies were analysed from the perspective of their apparent structural constituents. As Goodenough (1968 [1956]:93-94) wrote, the aim is a 'method and [...] its implications for developing an empirical science of meaning. The aspect of meaning to be dealt with is signification as distinct from connotation'. The 'meanings' of kinship terms in componential analysis are, as its appellation indicates, the result of reductions into elementary components, such as 'gender', 'generation', 'lineality' or 'laterality'.

That these basic semantic units or distinctive features, and the 'meaning' they are supposed to convey, are for the most part etic characteristics is a problem. Meaning is essentially understood as the result of a successful dismantling (decoding) of an interrelational structure (the message), in this case 'terminology'. Gender and generation are not here so much cultural constructs as rather universally acknowledged characteristics with which systems have to deal. Componential analysis does not reveal a great deal about the emic or cultural constituents of a terminological set or of its Indigenous representation, but confirms when, where and which of the paradigmatic choices constitute the syntagmatic chain. As Kronenfeld (1980:166) writes,

[T] he measure of the success of a Lounsburian analysis becomes not how well it represents the way in which natives actually compute kinship, but instead how succinctly and accurately it summarises the (genealogical) regularities [...]. We do expect that what native speakers do should, in some well-defined way, be equivalent to the Lounsburian operations-but we do not require that native operations necessarily be identical to them.

Such a problem was among the reasons for componential analysis having 'officially' disappeared from the anthropological agenda, although its principle of decomposing a corpus into structural units survived in what d'Andrade (2000 [1995]) calls feature analysis, and its influences are transparent in most current approaches to kinship, including in this paper.

There have been other more recent cognitive approaches to kinship, such as the use of schema theory, which provides a view of culture as a model of 'simplified worlds' (d'Andrade 1992), and which is based on Bartlett's (1932) notion of schemata. Connectionist theory is a related approach. Developing ideas from parallel networking of learning processes (see for example McKellin 1995), these approaches have the merit of substituting an interest in the dynamics of cognition, especially learning processes, for the rule-governed aspects of the semiotic field underlying kinship terminologies. While I do not completely embrace either the semantic-componential analysis or the schema-connectionist approach in a strict sense here, I draw important aspects from both: the acknowledgement of a genealogy-based component in kin recognition from the former, and the central importance of learning the 'simplified worlds' of a system with respect to processes of category extension from the latter. The approach adopted here is also related to relative product analysis, which provides a 'cognitively "real" definition' of kin term categories, as it is based 'directly' on actual informant operations' (Kronenfeld 1980:151; see also Keen 1985).

$\mathrm{I}$ argue that three steps are necessary and sufficient for defining completely or absolutely a person's position in a Dravidian grid of kin categories. The first step is to describe the system's properties as it is based on the relationship between its components. These are a 
set of shared symbols (terms and categories) and algorithmic methods defining how the terms and categories are related and subsequently extended. The second step describes the initial-and to some extent arbitrarily defined-states from which extension can proceed. The last step explains how properties and algorithms are applied to 'genealogically unrelated' persons. Despite the somewhat ambiguous formulation above, I do not imply that the use of kin terms towards persons who are not genealogically close is strictly the product of a metaphorical extension, an approach' that has been terined 'polysemic' with regard to the 'meaning' of kin terms. Nor do I imply that classificatory kin terms have a unique semantic value throughout the grid of relationships (monosemy; see Hocart 1968 [1937]). This paper does not address the question of whether extension is based on, or reflects, monosemy or polysemy of kin terms (see Noricks 1987 for a discussion), but it does articulate the mechanisms inherent in such extensions.

The examples used in this paper to illustrate the pragmatic mechanisms inherent in the extension of kin categories is based on fieldwork among Ngaatjatjarra-speaking people, who are a dialectal group of the Australian Western Desert cultural bloc covering about $600,000 \mathrm{~km}^{2}$ and consisting of more than 40 such dialectal groups (Berndt 1959). The Ngaatjatjarra have a kinship system that had been named by Elkin (1938-40) the Aluridjatype. This is not the place to discuss the specific features of this system in detail, especially since its depiction by Elkin is in some respects erroneous (see Dousset 1999a, 1999b, 1999c, 2002, 2003). The most important aspect to consider here is that, despite some of the earlier ethnographies, Ngaatjatjarra and other Western Desert peoples operate a bifurcatemerging type of cross-cousin classification and that (most) cross-cousins are also potential spouses. From a componential point of view, it is a system in which generation and gender are the properties engaged to determine the distinction between cross and parallel kin. In most cases, this distinction is also congruent with that between affines and consanguinesin most cases only because close cross-cousins, such as actual first and usually second cross-cousins, are considered to be too close and to share too much substance to be potential affines. Close cross-cousins are therefore referred to as 'brothers' and 'sisters', but this practice has only a temporary effect on actual relationships and has no implications for other people's category assignment or the system's general properties (see also Tonkinson n.d., 1991[1978]:64).

\section{SOME GENERAL CONSIDERATIONS ON THE KINSHIP SYSTEM AND ON SOCIAL CATEGORIES: DEFINING THE PROPERTIES AND ALGORITHMS}

Héritier (1981:175, quoted also in Viveiros de Castro 1998:345) wrote that 'once we leave the range of first cousins, there is no simple and universal criterion that would allow us to establish in objective terms the cross or parallel character of a relationship of consanguinity'. Viveiros de Castro goes on, rightly in my view, to explain that, on the contrary, there is a means, which is, for any person, by way of 'his or her equivalence to primary genealogical relatives'. Elsewhere in the same paper (1998:347), he explains that '[f]or each sex taken as a term, the opposite sex is purely a relation, or rather, a conductor of consanguinity and affinity relationships between individuals of the same sex'. The author introduces herewith the basic principle of the 'relational triangle' I will be proposing below. He does not, however, follow this path and restores in the same paper the local-global distinction in which 'global' systems, such as Australian, seem to lack the generalised use of conductors and hence need social categories in order to determine marriage 'classes'. Despite the acknowledgement of the existence (versus use) of conductors, the conflation of social categories with kin terminology at an identical analytical level prevails. We shall see below that both Héritier's claim and Viveiros de Castro's reiteration of the global formula for Australia are mistaken: Australian, and in particular Western Desert, systems know both the local and the global formulae. 
The processes at work in the determination of a person's kin category comply with a set of properties, which are usually summarised in the notion of 'kinship system'. A kinship system defines here the rules of kin classification and the associated terminology and marriage regulations defined as prescriptions or proscriptions. Associated to it is a genealogical grid, which is the result of a certain degree of compliance with the system and its jural (proscriptive) and structural (prescriptive) principles for defining culturally acceptable spouses. In Aboriginal Australia, and certainly among Ngaatjatjarra-speaking persons, these properties, proscriptions and prescriptions are explicitly stated by Indigenous peoples in the form of a discourse on ideal typical or expected behaviour. Alliance prescription is defined as a compulsory cross-cousin marriage: a kumnili's (FZ) and a kamuru's (MB) yumtalpa/katja $(\mathrm{D} / \mathrm{S})$ is the regular spouse. Proscription is explained as an interdiction against marrying close cross-cousins (in English 'too close'), but it may also be expressed as a prescription in suffixing the terms kurntili and kamuru with the property tjiwankatja ('from long way') (see Dousset 1999a \& 2003). Conformity with these rules is as high as $97 \%$.

The terminological system's properties themselves are not explained in such structural ways, but are depicted as the expected consequences of proper marriages contracted in preceding generations. According to the basic bifurcate-merging principle, a kamuru (MB) is the brother of ngunytju (M), mamies a kumtili (FZ), who is the sister of mama (father) and gives birth to watjirra (cross-cousin). All other co-generational collaterals are tjurtu.(B) and kurta (Z). While Ngaatjatjarra terminology includes more than 20 terms, the five mentioned above form the nucleus of the system's properties, and are also those that are applied in processes of kin category extension. In some respects, they define d'Andrade's (1992) 'simplified worlds': they establish the basic model of which each actual case of kin-relation is one particular instantiation. Watjirra is a case on the boundary, as it is itself a composite category sometimes described as kamumu-ku katjalyurntalpa (MB/WF/HF's S/D) or kumtili-ku katja/yumtalpa (FZ, WM/HM's S/D), which are what Keen (1985:63) terms 'kin-relational expressions', and can be considered as already containing an instantiation of the relational triangle with its three positions or corners: Ego, a $\mathrm{MB} / \mathrm{FZ}$, and its $\mathrm{S} / \mathrm{D}$ (see below).

In the process of kin category recognition, some of the terms are categories of the simplified world. Such is the case with kumtili (FZ), kamuru (MB), yumtalpa (D) and katja (S) and, to a lesser extent, watjirra (cross-cousin). Others are instantiations of particular relationships within these categories that add information not needed in kin recognition but detailing particular relationships and life-trajectories. This is the case with terms such as tjamirti (actual female cross-cousins referring to each other), yumari (FZ that is a potential or real WM) or waputju (MB that is a potential WF). An actual wife's father is referred to as waputju, although he is part of the kamuru category and although, in the construction of the relational triangle, it is this latter term that would be used.

The most important structural trait of the system operates in Ego's parents' generation. Characteristically for bifurcate-merging systems, $F Z$ is distinguished from $M$, and $M B$ from $F$, but $F$ and $F B$, as well as $M$ and $M Z$ are not. $A M B$ marries a $F Z$ and their offspring are crosscousins and fall into the affinal category. There is no terminological distinction between types of cousins, such as between first and second cross-cousins. As alluded to above, the only distinction made is a proximity-distance evaluation, resulting in a consideration and treatment of first, and sometimes second, cousins as siblings (they may nevertheless be addressed by the cross-cousin terminology as well). This distance is measured with respect to genealogical memory, which is usually limited to two ascending generations. In other words, a cross-cousin with whom one cannot trace a direct ascending genealogical link is distant enough to be an actual affine and may, if of the opposite sex, be referred to as kurri (spouse).

Table 1 reproduces an extract of the terminological grid of the Ngaatjatjarra dialect. The terms that constitute the genealogical nucleus or the 'simplified worlds' that are used in relative products are underlined. Synonyms and most contextually based and descriptive terms have been omitted. 
Table 1: Extract from the Ngaatjatjarra kinship terminology (underlined terms are part of the genealogical nucleus or 'simplified worlds')

\begin{tabular}{|c|c|c|c|c|}
\hline & \multicolumn{2}{|l|}{ Males } & \multicolumn{2}{|l|}{ Females } \\
\hline & cross & parallel & parallel $\therefore-\cdots$ & cross \\
\hline$G+2$ & \multicolumn{2}{|c|}{$\underset{\operatorname{kurri}(\mathrm{M}(\mathrm{MF}=\mathrm{H})}{\operatorname{tamm}}$} & \multicolumn{2}{|c|}{$\begin{array}{c}k(l), a r l i \\
k m r i\left(\mathrm{mFM}=\mathrm{W}^{\prime}\right)\end{array}$} \\
\hline $\mathrm{G}+1$ & $\begin{array}{l}\text { kammun (MB) } \\
\text { waputu (SpF) }\end{array}$ & mama & 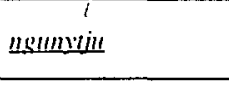 & \begin{tabular}{|l|} 
kmmutili $(\mathrm{FZ})$ \\
ymmari $(\mathrm{SpM})$ \\
\end{tabular} \\
\hline G-0 & $\begin{array}{l}\frac{\text { watiirra }}{\text { kunri }(\mathrm{H})} \\
\text { marutju (actual WB) }\end{array}$ & 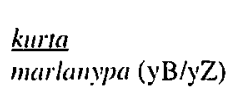 & $\frac{t w m+u}{m a r k m y p a(y B / y Z)}$ & $\begin{array}{l}\frac{\text { watiime }}{\text { kumi }(\mathrm{W})} \\
\text { ijwwari (aclual HZ) }\end{array}$ \\
\hline G-1 & $\begin{array}{l}\text { yıkari } \\
\text { waputju (DH) }\end{array}$ & $\underline{\text { katia }}$ & zurmalpa & $\begin{array}{l}\text { yukari } \\
\text { mingkayi (actual SW) }\end{array}$ \\
\hline G-2 & \multicolumn{2}{|c|}{$\begin{array}{l}\operatorname{liamu} \\
\text { kurri (IDS = H) }\end{array}$} & \multicolumn{2}{|c|}{$\begin{array}{c}\text { kaparli } \\
\text { kurri }(\mathrm{mSD}=\mathrm{W})\end{array}$} \\
\hline
\end{tabular}

The nucleus is constituted by ngunytju (M), mama (F), kamuru (MB), kurntili (FZ), yurnalpa (D), katja (S) and to some degree watjirra (cross-cousin). The relationships between these terms are combined and extended and constitute the terms used to create relative products. Here are a few examples. Kurri is not part of the nucleus since my kurri's children are also mine and would hence be described as [ngayu-ku] yurntalpalkatja ('[my] daughter/son'). Kamuru (MB) could be theoretically produced through the wording ngun$y t j u$-ku kurta ('a mother's brother'). This however is never done since kamuru is itself a term from which relative products are constructed, such as kamuru-ku yurntalpa ('MB's daughter') which may or not be a spouse (kurri). Kurri itself is not used in relative products. Katja-ku yurntalpa, another example, is a son's daughter and a particular case of a kaparli. The latter term is not used in relative products. Cross-cousins are expressed in three ways. Either as kamuru-ku yurntalpa/katja ('daughter/son of a mother's brother') or kurntili-ku yurntalpa/katja ('daughter/son of a father's sister), or, a third possibility, through the use of watjirra (general cross-cousin) in its straight form. Watjirra however is usually only used as a direct address or reference, and only in very few occurrences was it used as the constituent of a relative product. Yet another example: MMZD is Ego's M (ngunytju), since Ego's mother refers to her as tjurtu (Z) and any mother's sister (ngunytju-ku tjurtu) is one's mother. However, Ego's MMZS is a kamuru and his children are Ego's 'cross-cousins', since Ego's mother calls him brother (ngunytju-ku kurta). In the last two cases, $\mathrm{M}$ is the conductor.

As we can see from these examples, the relative products are fragmented into equivalences that reflect componential analysis and the principle of bifurcate-merging. Relative products can only be constructed if there is regularity in the relationships between the terms of the genealogical nucleus. In this sense, the phrase ngunytju-ku kurta ('a mother's brother'), for example, is rarely heard in everyday usage since it is inferred in the word kamuru (MB). It would only be suggested when the properties of the relationship need to be articulated.

These procedures are fairly straightforward when it comes to expressing one's relationship with people who are genealogically close or with whom interaction is recurrent. However, more than just a genealogical marker, kin categories need to be extended to embrace 'unrelated' persons as well: the system of kin-classification is universalistic, or 'total' and 'embracing the entire society', as Testart (1985:208) wrote. Radcliffe-Brown (1930-31:44) termed this principle the 'non-limitation of range' and Tonkinson (1991:57) explains how 'the moral universe of the Mardu is populated solely with relatives'. The properties summarised above hence need to be extended to include all members of society, and, in theory at least, humankind. Being attributed a kin relation towards other people, whether close or 
distant, is as natural as having legs and arms. ${ }^{6}$ This is the point where, according to Dumont and Viveiros de Castro, the 'global formula' comes into play.

The global-local debate is concerned with the mechanisms at work in the extension and application of kin categories to people with whom no genealogical relation can be determined or is remembered: foreigners or quasi-foreigners. I claim here that extensions in these cases do not need social categories (global formula), nor are they completely arbitrary. Because of the non-limitation of rangs, however, one might wonder what mechanisms are involved when, for example, someone calls a man 'father', even though no one has the capacity to trace a genealogical connection? How do these persons know that 'father' is indeed the correct term, and that 'uncle', 'brother', 'cousin', 'son', 'nephew', 'grandfather' or 'grandson' are not equally accurate?

This question is made even more convoluted by the fact that genealogical memory in Australia is usually shallow, and especially shallow in the Western Desert where the parents of the grand-parents are usually not remembered, and where, at the grandparents' level, actual genealogical relations are blurred and conflated, albeit in such a way that the kin category pattern is not altered. It is frequently the case in the upper generations-especially in $\mathrm{G}+2$ and when the grand-parents are deceased-that classificatory brothers associated with jdentical or related sites in the landscape are reduced into one named individual. Although rare, such conflations do also occasionally happen with sisters or a man's co-wives. The range in which kin category extension proceeds by known genealogical links is in fact fairly limited, and is only necessary for preventing close cross-kin from becoming actual affines.

The 'global formula' approach therefore suggests that social category systems such as sections and subsections fill the gaps when knowledge of the range of actual connections is limited: they are interpreted as an abstraction of the genealogical grid. Sections and subsections are labelling devices that are indeed generally compatible with the pattern of kin categories. They are ascribed by birth, depending on the parents' membership of a category, and in some regions work as ceremonial as well as totemic groupings. Ngaatjatjarra-speaking people of the Western Desert have a four-section system.

A four-section system divides society (and humankind) into four global and named categories. Among the Ngaatjatjarra, these are called Karimarra, Tjarurru, Purungu and Panaka. Additionally, Karimarra has a synonym Milangka, and Panaka has a synonym Yiparka. These global categories each merge various kin classes and are organised in accordance with filiation and prescriptive marriage rules. A Karimarra woman marries a Purungu man. This couple has Tjarurru children, who in turn marry persons of the Panaka section. Tjarurru women have Karimarra children, and Tjarurru men have Purungu children.

Provided we define a particular section as containing Ego (a male and a female, that is a brother and a sister), it is a simple exercise to draw a table reducing some of the kin categories mentioned in Table 1 into the section system (see Table 2)

Table 2: Kin categories and sections

\begin{tabular}{|c|c|}
\hline Karimarra & Purungu \\
\hline 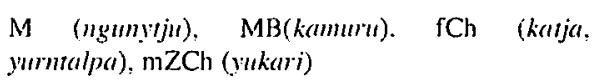 & $\begin{array}{l}\mathrm{F} \text { (mama). FZ (kwmili), (yumalpa), fBCh, mZCh } \\
\text { (jukari), mCh (kaija, ywaralpa) }\end{array}$ \\
\hline Tjarurru & Panaka \\
\hline $\begin{array}{l}\text { Ego, B (kurra), Z (tjuru), FF (tjammu), MM } \\
\text { (kaparli), fDCh/mSCh (tjamu, kaparli) }\end{array}$ & $\begin{array}{l}\text { MBD, MBS, FZD, FZS (watjirra). H, W (kurri). MF } \\
(t j a m i), \text { FM (kaparli), mDCh/fSCh (tjamu, kaparli) }\end{array}$ \\
\hline
\end{tabular}


Using the section system instead of specific kin categories and relative products for determining relationships becomes a tempting procedure. Indeed, all one would have to remember are four terms, each divided into two gender categories. For example, if Ego is Tjarurru, then it suffices to know the general relationships as presented in Figure 1:

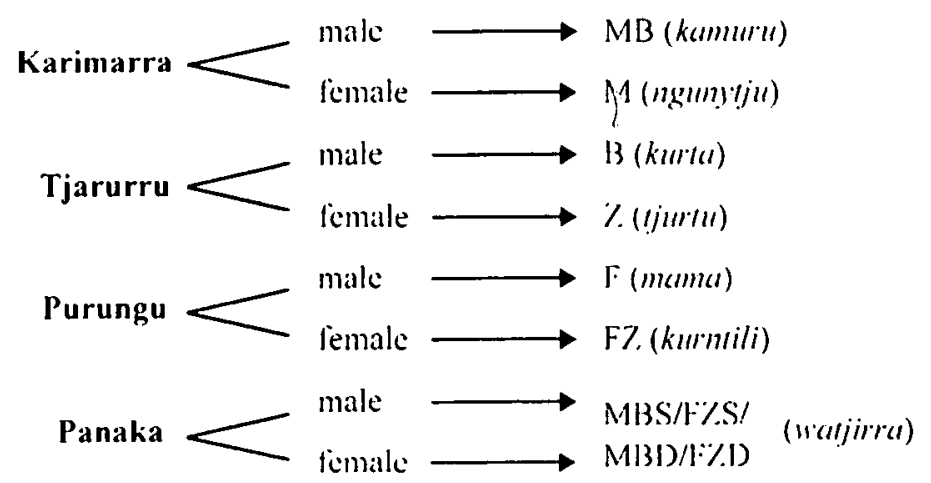

Figure 1: Knowledge base for a Tjarurru Ego to be able to classify people in kin categories using the section system.

The figure reads as follows. If a Tjarruru encounters a Karimarra, and this Karimarra is a male, the latter is of the kamuru (MB) category. If, on the other hand, this Karimarra is a female, then it is a ngunytju (M). Watjirra can be either female or male, at least in this region of the desert. The male connotation is unmarked. The marked female version needs an additional explanation such as watjirra kungka (lit. 'a cousin female'), or the use of one of the synonyms (or sub-classes) such as kurri (H/W) or tjamirti; the latter is however only used between two females.

At first sight, sections therefore do appear as ideal guides in processes of kin category determination between persons of unknown genealogical connection. Because they are ascribed by birth and distinguish, to some extent at least, kin categories, they were seen as a 'ready-reference index' (Fry 1933:267) and, in some cases, they are indeed used as such when foreign people of distinct languages or tribal affiliations meet (Lawrence 1969 [1937]; Service 1960; Strehlow 1999). On the other hand, however, they only propose a first approximation, as they do not distinguish kin categories with sufficient certainty. As Table 2 above illustrated, various categories are conflated into one section.

The second problem is that sections or subsections are not known and used everywhere, despite their wide diffusion throughout the continent (McConvell 1985, 1996). The Ngaatjatjarra, for example, did not have the section system until the 1920s or 1930s, when it arrived from neighbours to the West, while their kinship system was already of the bifurcate-merging type as genealogies demonstrate. It has been suggested that, whether used or not, named or not, sections underlie the kin category system (e.g. Denham el al. 1979; Long 1916; Viveiros de Castro 1998; but see also Allen's 'tetradic' model in 1986, 1998). But can such unnamed or unknown structural devices really serve as conductors in everyday kin category recognition?

This leads me to the third and final serious flaw in the explication of kin category determination by way of the global formula: it is simply ethnographically ungrounded, at least in this part of the Western Desert. When collecting genealogies in the field, I did overlap the section system with the genealogical grid as a means of verifying relations. The accuracy of this overlapping was usually received with surprise and some amusement. Although people obviously know that sections are compatible with kin categories, the former seem to be part of a distinct cognitive level. Sections are unambiguous and unalterable labelling devices and are usually not used and interpreted within the egocentric and dynam- 
ic domain of kin category determination and the representation of the genealogical grid.

This however needs to be contrasted with reports from other regions. In Central Australia, among the Warlpiri and Arrernte people for example, social category systems seem to occupy a much more important role in everyday interaction and personal address than they do in the Western Desert. It is however also necessary to add that the Warlpiri, as well as the Northern Arremte, have eight subsections, instead of four sections, which are linguistically distinguished in accordance with gender, generating 16 social categories. It is obvious that this system of social categories with a large number of discriminatory terms is a much more efficient and precise means for classifying kin than a section system with only four discriminatory elements. On the other hand, it might well be that the significant use of subsections among Central Australian and other groups is the consequence of the modified means of communication and transportation, resulting in intensified social interaction over large distances and among various language groups, where sub-sections function as a lingua franca of kinship (Dousset 2005, see also Strehlow 1999). The discussion below does not take these Central Australian (and other) cases into account, but reports the mechanisms at work in groups with four section systems, particularly in the Western Desert. Let me now describe these mechanisms, demonstrating that the local formula is applicable in the Australian case as well.

\section{THE ARBITRARINESS OF INITIAL STATEMENTS: DEFINING THE CONSTANTS}

In order to instantiate the properties of kin-classification, initial constants from which extension takes place are necessary, both in analytical terms and in actual social processes. There are two situations for the determination of these initial constants. The first and less common situation is one in which an 'absolute' foreigner, with whom it is certain that no pre-existing relationship to anybody else known can be established, is introduced into the 'community'. The process of engendering the initial constant that allows for subsequent classification and application of relative products inside the grid of kin categories in this case is 'arbitrary'. The second situation, however, reflects one in which a new person is born into the existing genealogical grid. In this case, the initial constant is set by way of recursion, where pre-existing relationships define and are simultaneously re-defined in accordance with the system's properties. We shall see that this process is constituted by the basic scheme or simplified world from which extension proceeds.

\section{Situation 1: What shall we do with a foreigner?}

As already mentioned above, incorporation into the system of kin categories is an imperative for social interaction. It is a 'natural' fact that people are 'kin'; being kin, however, does not induce or necessitate a genealogical connection, being in many cases the result of a logical or algorithmic extension of the properties of the genealogical nucleus and associated category pattern. Kin categories place people inside a scheme of reciprocal or embedded values and norms by structuring the social field. Kin categories define the interval of expected and appropriate behaviour, be it ceremonial, matrimonial, economic, or simply in everyday interaction. Each kin category is tied to such a behavioural interval (Tonkinson 1991 [1978]:63): from restraint and obedience to partial avoidance of a MB (kamuru) and complete avoidance of a FZ (kurntili) who is a potential WM (yumari); from a respectful and restrained but close and intimate attitude to a relaxed and joking relationship with a cross-cousin (watjirra); from a solidarity-driven but hierarchically marked attitude to an obedient restraint-relationship with $\mathrm{M}$ (ngunytju) and F (mama); and so on. Once the relationship is established between two persons, the behavioural attitude expected between their categories is adopted, and is only later adapted to the actual situation, while still being framed within the normative interval. 
This process is rendered somewhat more complex by the absence of remembered genealogical or affinal connections. As Von Sturmer (1981:13) explains, 'even Aborigines are called upon from time to time to meet up with people - including other Aborigines whom they do not know.' He contimues, 'they are awkward situations, and there are no set mechanisms for resolving them easily'. Von Sturmer quotes an example that is particularly revealing and which I have decided to reproduce entirely here. It reports the dialogue between two Aboriginal men who have not met before: !

Mareeba man: 'Where you from?'

Mickey: 'I'm Exward River man. Where you from?'

Mareeba man: 'I'm Lama Lama man... do you know X?'

Mickey: 'No. Do you know Y?'

Mareeba man: 'No. Do you know Z?'

Mickey: 'Yes. She's my aunty.'

Mareeba man: 'That old lady's my granny. I must call you daddy.'

Mickey: 'I must call you boy. You give me cigarette.'

As we can see from this example, both men try to find a common nodal person, a connector, and as soon as it is found, it instantiates a formal behavioural pattern: Mickey, being the father of the Mareeba man, feels he is entitled to ask for a cigarette. One could even argue that the relationship is only established once it is satisfied by the unilateral demand for sharing, adding to a rather abstract relationship between categories (F and $S$ ) a relationship of expected behaviour.

The most extreme of these kinds of encounters is that of a 'perfect stranger' entering an existing community: how should one behave towards such a person, where does the person stand in the field of social interaction? The reverse procedure is adopted in this case in answering the following type of question: 'What type of relationship do I expect to be entertaining with this person?'. Depending on the answers to these questions, a kin category is attributed or negotiated. Such was the case when I myself first arrived in a Western Desert community, accompanied by a local woman whom I had already known for some time. We were of similar age, and while age and generation cannot be conflated in Aboriginal kinship systems (Testart 1995), it is nevertheless a feature that is taken into account in such situations. I could, therefore, be either her cross-cousin (watjirra), and hence a potential spouse, or a slightly younger brother. Accompanying me into the community vested her with a certain degree of responsibility. In the eyes of the community, she could be held accountable for my wrongdoings. Classifying me into the cousin category would have been problematic, for it would have given rise to ambiguous interpretations of our relationship as potential spouses and would not have allowed her to exert any authority over me. She had obviously been thinking about these matters and presented me to her parents as her younger brother marlanypa (this is the marked alternative of kurla), a tjurtu (Z) exerting some authority over her marlanypa. Her parents immediately called me katja (son), and it did not take long before they expected services from me, such as gathering firewood and sharing food. Thus, in the case of foreigners, the normative consequences of the system's properties are taken as the determinants for the mutual kin categories. The equation is resolved the 'other way round', so to speak. Normative behaviour, which is one of the consequences of typified kin category relations is reversed so as to become the determining argument in kin category attribution.

The case illustrated above, however, occurs quite seldom, as the number of foreigners arriving in such communities is limited. In fact, the motivated mode of determining a kin category illustrated above rarely happens between Aboriginal people. Even people living in distant communities with distinct languages can usually trace their mutual kin categories by recollecting at least one pre-existing link, as von Sturmer's example illustrates. 


\section{Situation 2: Born into and never get out}

The most usual case of kin determination is that of a person being placed within the grid of categories by birth. The mechanisms involved in this process are straightforward. I will nevertheless illustrate them since they will enable me to clarify what 1 propose to call the 'relational triangle'. The instantiation of a child as the node of its network is automatic and proceeds by simply applying the system's properties to the genealogical grid. The kin category of a child is pre-defined in accorcance with its parents' kin categories: it becomes the 'parents' child', son or daughter, and, therefore, the mother's brother's and father's sister's 'niece' or 'nephew', its siblings' brother or sister and so on. Within the community of the extended and co-residential family, the child's relationships to people are 'inherited' from its parents' relationships. If a person in the community calls the mother of this new child kumtili (FZ), for example, then the child simply becomes a kumtili ku yumtalpa/katja (FZD/FZS) and therefore a watjirra. The values necessary to instantiate the child's network hence result from a property-congruent extension of known relationships, whether genealogically based or not.

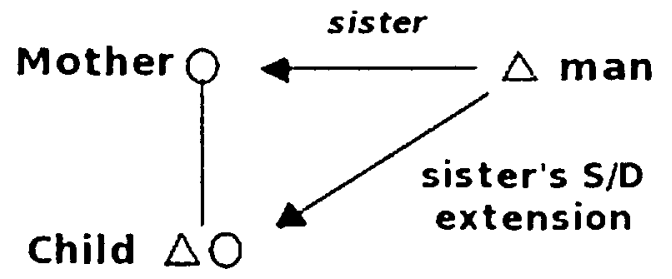

Figure 2: Determination of a newborn child's category, a simple relational triangle

The process can schematically be illustrated as in Figure 2. A man calls the mother of the child 'sister'. This is in the realm of knowledge inherited from previous relationships. In a following cognitive step, the man automatically extends his relationship to the child from this knowledge. The child becomes a 'sister's child' that is, a nephew or niece (yukari), and not a daughter (yumtalpa) or a son (katja). Moreover, he can immediately deduce that this yukari may be his children's spouse. These relationships are mechanical and not modifiable.

Once the Dravidian type of bifurcate-merging feature applies to a community, extension and calculation of relationships to newborn babies is a simple process that flows directly from pre-existing (genealogical) relations and the system's properties. This elementary process, however, defines the procedures that are necessary and sufficient in the determination of two 'non-related' people's kin category. What emerge from this procedure are the three basic principles inherent in what I call the relational triangle:

1) In order to determine the relationship between two unrelated persons, a third and intermediary person is necessary. I will call this person the 'nodal point' or connector. In the case quoted above, the mother constitutes this nodal point.

2) Both persons' relationships to the nodal point are either mechanical or known (i.e. the memorised result of a previously applied analogue procedure).

3) The relationship between the two persons is deduced from the combination of the two relationships with the nodal person by applying the system's properties in the form of relative products. For example, one's kamuru-ku yurntalpa (daughter of a MB) is a watjirra (cross cousin), and kamuru itself is one's nguny:ju-ku kurta (the brother of a mother).

These three steps are necessary and sufficient in kin category recognition and determination. No social calegory system is required; no "global formula" is a condition. 


\section{THE RELATIONAL TRIANGLE: EXTENDING THE GENEALOGICAL NUCLEUS}

In the real world, it is not necessary to memorise one's relationship to everybody else. This would indeed be beyond the memorising capacity of an average person, considering that there are probably more than 4000 to 5000 persons just in the Western Desert cultural bloc, which is composed of dialectal groups that regularly interact.

A complete overview of the genealogical grid, including knowledge of generations of connections and their inheritance, is not necessary for kin classification to be operational and property congruent. The process illustrated here through the schema of the relational triangle is a sufficient but necessary mechanism, through which every person is capable of deducing how he or she stands in relation to every other person. The relational triangle provides a procedure or algorithm, as well as a cognitive model reflecting how people do in fact determine the kin category in which they stand to each other without genealogical knowledge being a condition. It is not a formal or structural model, but the abstraction of what I believe to be mental representations; and, in this sense, it is also an emic heuristic model.
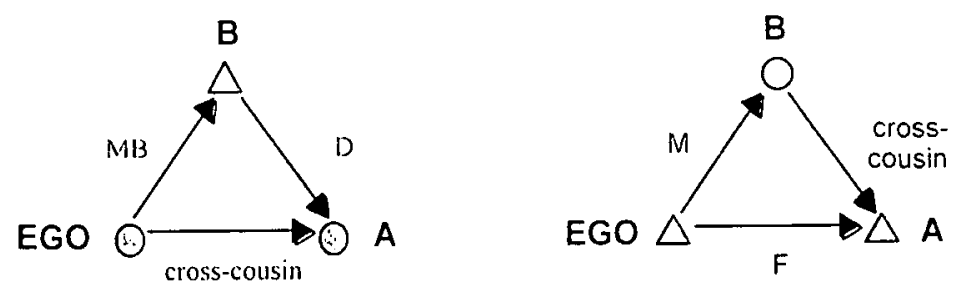

Figure 3: Two examples of the relational triangle

Figure 3 illustrates two examples of the relational triangle. In the first, suppose two women meet, neither knowing how she is 'related' to the other. Let us nominate the first woman as Ego, and the second A, They will try to find a third person in common for whom each knows her memorised relationship. This third person, the nodal person, is in our example a man, B. He does not have to be genealogically related to any of these women. His relationships may have been previously elaborated using the same method. Let us suppose that Ego calls B kamuru (MB), the latter reciprocates with yukari (ZD). Let us also suppose that $B$ calls A yurntalpa (D), and that she reciprocates with mama (F). From their relationships to the nodal person, Ego and A know that they must be in a cross-cousin relationship (watjirra), since one's kamuru's daughter is a watjirra.

The second example involves a slightly more complex process. Ego calls B 'mother' (ngunytju), and this mother'calls the man A 'cross cousin' (watjirra). Because a crosscousin is in the spouse-category, one's mother's cross-cousin is, obviously, one's father. Ego therefore calls the man A 'father' (mama), and A reciprocates with 'son' (katja), since Ego knows that a ngunytju-ku kurri or ngunytju-ku watjirra (mother's husband or male crosscousin) is a mama $(\mathrm{F})$.

The basis for determining two persons' relationship is a property congruent extension of the terms and classes inherent in the simplified world of what I named the genealogical nucleus. Mentioning the case of the grandparents is useful here to get further understanding of the principles of these cognitive processes as they work among the Ngaatjatjarra and other Western Desert peoples. Indeed, they are never used as nodal persons because these positions are not sufficiently discriminatory and not economic. A tjamu (grandfather) can be a MF as well as a FF. There is hence no way the term tjamu can induce a distinction between mama (F) and kamuru (MB), or between ngumytju (M) and kurntili (FZ). The same applies for kaparli (grandmother/granddaughter). This is possibly different in other Australian systems where the distinction of cross and parallel grandparents and grandchildren is relevant. 
However, more generally speaking, choosing a person of the $\mathrm{G} \pm 2$ generation as a node is an unnecessary and uneconomic complication of the procedure since every relationship can be described as a relative product of the two generations closest to Ego.

For similar reasons, niece (yukari [yumari, mingkayi]) and nephew (jukari [waputju]), are other classes avoided as nodal points. It seems more obvious to memorise these classes as a child's cross-cousin or spouse, rather than as an opposite sex sibling's child. The positions or relations which are taken into óccount are therefore those that clearly distinguish gender and generation within the nuclear family and among the parent's siblings (Table 3): they are the application of relative products of componential properties.

Table 3: Discriminatory relationships used as nodal points: the 'genealogical nucleus' or 'simplified world'.

\begin{tabular}{|c|c|c|c|c|}
\hline Term & English gloss & gender & generation & Cross-kin \\
\hline Ngunyıju & mother & $f$ & $\mathrm{G}+1$ & \\
\hline Kamuru & uncle & $\mathrm{m}$ & $\mathrm{G}+1$ & cross \\
\hline Mama & father & $\mathbf{m}$ & $\mathrm{G}+1$ & \\
\hline Kurmili & aunt & f & $\mathrm{G}+1$ & cross \\
\hline Tjuru & sistcr & f & G-0 & \\
\hline Kuma & brother & $\mathrm{m}$ & G-0 & \\
\hline Yumalpa & daughter & f & G-1 & \\
\hline Kaija & son & $\mathrm{m}$ & G-1 & \\
\hline \multicolumn{5}{|c|}{ Additional category somctines used, but structurally not necessary } \\
\hline Watjirra & cross-cousin, "MBCls", $\mathrm{FZCl} "$ & $\mathrm{f} / \mathrm{m}$ & G-0 & cross \\
\hline
\end{tabular}

What is further interesting is that the genealogical nucleus constituting the basic classes applied in category-extension and relative products complies astonishingly well with Greenberg's (1990[1980], 1966:72-87) formalisation of kinship terminologies with respect to marked and unmarked characteristics.

\section{GREENBERG, MARKEDNESS AND RELATIVE PRODUCTS}

Drawing on Kroeber's (1909) analysis of kinship terminology with reference to eight categories (generation, lineal versus collateral, age difference in one generation, sex of the relative, sex of the connecting relative, sex of the speaker, consanguinal versus affinal, and condition of the connecting relative), which later became the bases for componential analysis, Greenberg (1990[1980], 1966:72-87) attempts to apply the concept of markedness to the analysis of universal aspects of terminologies. 'Markedness, is the name given by N. Trubetzkoy and R. Jakobson in the 1930s 10 "the asymmetrical and hierarchical relationship between the two poles on any opposition" (Waugh 1982:229)', explains Scheffler (1987:203) in a critical reconsideration of Greenberg's hypothesis with respect to systems of kin classification. 'It is best explained through an example. The French word 'homme' designates a male human being, while 'femme' designates a female human being. In this context, the two words are in an opposition. However, the opposition is not equivalent but hierarchical, since 'homme' may also mean human being in general, disrespectful of the 
gender attribute. According to the markedness theory, the word 'femme' is considered marked against the word 'homme' since the former is also included in the latter.

Greenberg (1990[1980]:317-318) summarises markedness in four characteristics. First, the marked member of an opposition is relatively complex in relation to the unmarked one. The second is that the unmarked category tends to have more distinctions than the marked category. The third characteristic is defectivation of the marked member, that is it lacks certain categories present in the unmarked member. The fourth characteristic is the greater text frequency of the unmarked category. Greenberg further'explains that 'if we investigate these and other marking properties in regard to Kroeber's kinship categories, we find unmistakable evidence of the existence of marking hierarchies' (1990 [1980]:318). For example, he explains, in "English, the absence of sex distinction in the collateral term "cousin" as against its expression in the corresponding lineal terms "brother" and "sister" is evidence for the marked status of collateral as against lineal. The absence of a term cousin-in-law as against the existence of brother-in-law and sister-in-law is further evidence of the same hierarchy by defectivation.' Greenberg summarises the marked-unmarked characteristics as they seem to be universally reflected in kinship terminologies through the following oppositions:

Lineal is unmarked as against collateral, consanguineal is unmarked as against affinal, male is unmarked as against female in regard to sex of nodal person, older is unmarked in relation to younger. In regard to generation there is a more complex set of relationships. In general, the closer a generation is to ego, the more unmarked it is. Likewise, each ascending generation is unmarked in relation to the corresponding descending generation (Greenberg 1990[1980]:318).

The above-mentioned genealogical nucleus used in relative products, Ngaatjatjarra's 'simplified world' of kinship terminology, astonishingly reflects those properties Greenberg notes to be universally unmarked. Let us recall the example of FZ (kurnili) and WM (yumari). They are in an opposition with respect to marriage and genealogical distance, since the former designates a close aunt and the latter an aunt who is a potential or actual wife's mother, and thus a distant aunt. The axis of opposition here is one of proximity/distance or of consanguinity/affinity. Kurntili may however be used to designate both these cases as well, and often is, as it is applied to the general FZ category. Kurntili is in this respect unmarked against yumari. As Greenberg hypothesized, genealogical distance is here marked and genealogical closeness is unmarked.

Another example is ijurtu and kurta (older sister and older brother), since they are indeed unmarked against marlanypa (younger sibling), and are part of the nucleus. Marlanypa is never used as a connector. Or let us note watjirra, which is usually used as a male cross-cousin when connecting to other relations, the female connotation being marked. Moreover, instead of using yukari ( $\mathrm{mZCh}, \mathrm{fBCh}$ ) as a nodal point, 'children's crosscousins' (yurntalpa/katja-ku watjirra [or kurri] lit. 'the son's cross-cousin [or spouse]') is the preferred product of these classes. This procedure, from Ego's point of view, confirms the preferential use of an unmarked category (parallel or consanguinal kin) as nodal point. Grandparents and grandchildren are not used, and generations close to Ego's comprise the favourite nodal points. Ascending, rather than descending, generations are preferred.

In a discussion on cognition and formal analysis of terminologies, Kronenfeld (1995) remarks that the 'idea of a system of terms (vs. a distinct list of referents for each term in a list) is to reduce cognitive load [...]', and he suggests that 'systematic redundancies might be presumed by native speakers-as a kind of default-leaving only specific marked/flagged exceptions to be specifically separately learned'.

The classes used in the relational triangle and constituting the simplified world of Ngaatjatjarra kinship clearly express an 'economy' of terms and principles that reflect 
Greenberg's universals formulated with regard to the unmarked/marked distinctions in kin terms and kin-classification, and that leave room for marked exceptions to be learned and to reflect more particular situations.

Being placed in a kin caltegory in relation to everybody else is a 'natural' condition in Aboriginal Australia; it is a condition of embeddedness in 'social place'. In the case of the Ngaatjatjarra, this embeddedness follows the bifurcate-merging principle, and is based on the extension of those primary genealggical relations (the genealogical nucleus) that are, generally speaking, unmarked. These discriminatory positions constitute the criteria followed in the searcl for a nodal point. In the case of an 'absolute foreigner', a category is 'arbitrarily' defined in accordance with the context of interaction. In most cases, however, kin categories are determined by way of previous applications of the relational triangle, whose results are memorised and constitute new nodal points. Therefore, kin recognition is not conditioned by deep genealogical knowledge or by the existence of social category systems. The local formula is at work.

\section{CONCLUSION}

Using the particular example of the Ngaatjatjarra-speaking people of the Western Desert, this paper's aim was to illustrate the cognitive processes involved in the classification of people into kin types in Aboriginal Australia. These processes, which I have summarised under the notion of the 'relational triangle', are defined by a set of constants or initial positions that are learned and remembered, and by the extension of nuclear genealogical connections in accordance with the system's classificatory properties. The initial positions, however, are themselves most often the result of previously applied relational triangles. In this sense, this paper has shown that category determination is the expression of a 'local formula'. While sections and subsections are important features of Aboriginal Australian social organisation, they are not unique to this continent, nor are they ubiquitous, and they are not devices that can or do respond accurately to the need for extending kin categories wherever there is social interaction or where such interaction is expected. The distinction between the Australian 'global' and the Dravidian 'local' formula loses its justification.

The relational triangle is, for obvious reasons, only applicable when the cross-cousin calculus is of the Dravidian type, as it depends on a mode of extending the genealogical nucleus that is consistent throughout. In this sense, Kronenfeld's (]989:93, 2001:429) characterisation of Dravidian cross/parallel, or in our case Western Desert Aluridja and many other Australian, systems as being 'socio-centric' is particularly accurate. Determination of cross or parallel kin is consistent throughout the network in such a way that a parallel cousin's cross-cousin is without exception a cross-cousin and always falls into the affinal category. This is not the case in an lroquois type of cross-classification where two persons related as parallel cousins may not have identical relationships towards a third person. Kronenfeld therefore characterises this system as egocentric. The major difference is that, in a Dravidian system, each relational triangle is reusable by anybody else, while this is not the case in an lroquois system where the applicability of other people's relational triangles depends on Ego's own position. The systematic, extensive and successful application of the relational triangle among the Ngaatjatjarra confirms that, despite what Trautmann and Barnes (1998) proposed following Elkin's (1938-40) characterisations, the Aluridja kinship system cannot be of the Iroquois-type, but must be Dravidian (see Dousset 2002).

The relational triangle is construed empirically upon a set of terms that reflect the simplified world of Ngaatjatjarra kinship, and proceeds by way of the two principles identified by Keen (1994:81) for the Yolngu of Arnhem Land: 'inherited kinship', which describes the transmission of mutual kin categories without the need to know actual genealogical relationships; and ' $\mathrm{kin}$ found through common distant connections', which either proceeds through 'inherited kinship' or through actual genealogical connections. 
While the elementary Ngaatjatjarra schema is based on genealogical relations and is in concordance with Scheffler's extensionist approach, the semantic units in the Ngaatjatjarra schema do not reflect unambiguously the components that result from a 'classic' componential analysis. Cross-cousin is itself a composed category, but functions in these cognitive processes as an independent class. There is formally no reason justifying the utility of crosscousins as nodal persons versus that of 'nephews' or 'nieces', unless we adopt Greenberg's theory on the markedness of terminologies. With respect to these questions, I have suggested that the genealogical nucleus (M, F, MB, FZ, B, Z, S, D, MBCh/FZCh) responds to an economy of emic category descriptions that are surprisingly consistent with Greenberg's principles mentioned above.

I believe this paper has successfully demonstrated that emic decompositions of kin categories may not always reflect the breakdown undertaken in formal analysis of terminologies and that neither genealogical depth, nor global social categories are necessary conditions in a system in which there is no limitation of range in extending kinship. One of the properties of a Dravidian type of bifurcate-merging system is the ability to 'memorise' virtual or classificatory positions without the need to remember all actual or calculated kin relations: the system itself is a device storing some of the aspects of social history.

\section{NOTES}

1. I am grateful to Victoria Burbank for stimulating my interest in the cognitive sciences and for her comments on an earlier version of this paper. I also wish to thank lan Keen, Gill Hutcherson, Pascale Bonnemère and the two anonymous reviewers for their helpful comments on an earlier version, David B. Kronenfeld for kindly sending me unpublished papers, as well as Patrick McConvell for pointing out the importance of the 'global/local" distinction, albeit on a slightly different analytical level from that applied here. Taken as a methodological concept, however, its implications are manifold. All of the above-mentioned are, of course, not responsible for any shortcomings in this article.

2. It is claimed that the Kariera people might not in fact have hat the kind of system that is described as being Kariera, just as the Iroquois peoples may not have had an Iroquois system (Kronenfeld 1989). As underlined by Trautmann and Barnes (1998), it is worth questioning the utility of typological labels that are based on ethnic names, and even on continent-wide conflations, as with the above-mentioned 'Australian' and 'Normal Australian' types. From an empiricist's point of view, and in the light of the above, doubts regarding expressions such as 'super-Kariera terminology', as proposed by Viveiros de Castro (1998), are legitimate.

3. However, one must add that Viveiros de Castro allows for 'concrete systems' containing both the local and the global formulae.

4. See, among others, Schneider (1965) and a discussion in Fogelson (2001); also Keen (1985) for a critique of structural semantic or componential analysis with respect to its 'cognitive validity' and 'psychological reality'.

5. See Malinowski (1929:525-526), and also Scheffler's work, for such approaches.

6. It is worth mentioning that the non-limitation of range is not a particular Australian feature, as testifies the example of the Yanomami (Alès 2001).

7. But sec also Greenberg's (1987) response in the sime journal.

\section{REFERENCES}

ALES, C. 2001. L'aigle et le chien sylvestre. La distinction de sexe dans les rites et la parenté yanomanni. Jn Sexe relaif ou sexe absolu? De la distinction de sexe dans les sociétés. Edited by C. Alès \& C. Barraud, pp. 157-200. Paris: Éditions de La Maison des sciences de l'homme.

ALLEN, N.J. 1986. Tetradic theory: An approach to kinship. Jommal of the Amhropological Society of Oxford 17(2):87-109

ALLEN, N.J. 1998. The prehistory of Dravidian-type terminologies. In Transformations in kinship. Edited by $M$. Godelier. T.R. Trautmann \& F.E. Tjon Sie Fat, pp. 314-331. Washington \& London: Snithsonian Institution Press.

BARTLETT, F.C. 1932. Remembering. Cambridge: Cambridge University Press.

BERNDT, R.M. 1959. The concept of 'The Tribe' in the Western Desert of Australia. Oceania 30(2):81-107.

D'ANDRADE, R.G. 1992. Cognitive anthropology. In New direcrions in psychological anthopology. Edited by T. Scluwartz, G.M. White \& C.A. Lutz, pp. 47-58. Cambridge: Cambridge University Press.

2000 [1995]. The development of cognitive anthropology. Cambridge: Cambridge Universily Press

DENHAM, W.W.. C.K. MCDANIEL, and J.R. ATKINS. 1979. Arandal and Alyawara kinship: A quantitative argument for a double helix model. American Ethmologist 6(1):-24. 
The 'Global' versus the 'Locil'

DOUSSET, L. 1999a. A la recherche des Aluridja: Parenté et orgaunisation sociale chez les Nganljatjarra du Déserı de l:Ouest anstralien. Unpublished Ph.D. thesis submitted at the Ecole des Hautes Etudes en Sciences Sociales, Parris.

1999b. L'alliance de mariage el la promesse d’épouses chez les Ngaatjatjarra du Désert de l'Ouest australien. Jownal de la Sociéré des Océanistes 108:3-17.

1999c. On reading Theodor Strehlow's 'Aranda regular and irregular Marriages'. Sirchlow Research Centre, Occasional Papers 2:45-59.

2002. Accounting for context and substance: the Australian Western Desert kinship system. Anthropological Fortum 12(2): 193-204.

2003. On the misinterpretation of the Aluridja kinship system type (Australian Western Desert). Social Antho. pology (forthcoming).

2005. Assimilating Identities: Social Networks and the Diffusion of Sections. Sydney: Oceania Publications, Monograph 57.

DUMONT, L. 1953. The Dravidian kinship terminology as an expression of marriage. Man 53-54:34-39.

1983. Affinity as a value: Marriage alliance in south India with comparative essays on Australia. Chicago \& London: University of Chicago Press.

1997 [197]]. Groupes de filiation et alliance de mariage: imtroduction à deux théories d'anthropologie sociale. Paris: Gallimard, coll. Tel.

ELKIN, A.P. 1938-40. Kinship in South Australia. Ocemia 8(4):419-452: 9(1):41-78; 10(2):198-234; 10(3):295$349 ; 10(4): 369-89$.

FOGELSON, R.D. 2001. Schneider confronts componential analysis. In The cultural analysis of kinship: The legacy of David M. Schmeider. Edited by R. Feinberg \& M. Ottenheimer, pp. 33-45. Urbana \& Chicago: University of lllinois Press.

FRY, H.K. 1933. Australian marriage rules. Sociological Review, 22:258-77.

GARDNER, H. 1987 [1985]. The mind's new science: A history of the cognitive revolution. New York: Basic Books.

GODELIER, M., T.R. TRAUTMANN, and F.E. TJON SIE FAT (eds.). 1998. Transformations of kinship. Washington, London: Smithsonian Institution Press.

GOODENOUGH, W.H. 1968 [1956]. Componential analysis and the study of meaning. In Kinship and social organization. Edited by P. Bohannan \& J. Middleton, pp. 93-124, Garden City, New York: The Natural History Press.

GREENBERG, J.H. 1966. Language universals with special reference to feature hierarchies. The Hague, Paris: Mouton \& Co.

1987. The present status of markedness theory: A reply to Scheffler, Journal of Anthropological Reserach, 43(4): 367-374.

1990 [1980]. Universals of kinship terminology. In On language: Selected wrinings of Joseph H. Greenberg. Edited by K. Denning \& S. Kemmer, pp. 310-327. Stanford: Stanford University Press.

HERITIER. F. 1981. L'exercice de la paremé. Paris: Hautes Etudes, Gallimard, Le Seuil.

HIRSCHFELD, L.A. 1986. Kinship and cognition: genealogy and the meaning of kinship terms. Curren Amhropology 27(3):217-242.

HOCART, A.M. 1968 [1937]. Kinship systems. In Kinship and social organization. Edited by P. Bohannan \& J. Middleton, pp. 29-38. Garden City: Natural History Press.

KEEN, 1. 1985. Definitions of kin. Joumal of Amhropological Research 4l(1):62-90.

1994. Knowledge and secrecy in an Aboriginal religion: Yolngu of North-East Amhem Land. New York \& Oxford: Oxford University Press \& Clarendon Press.

KROEBER, A.L. 1909. Classificatory Systems of Relationship, Journal of the Royal Anthropological Institute, 39: $77-84$

KRONENFELD, D.B. 1980. Particularistic or universalistic analyses of Fanti kin-terminology: The alternative goals of terminological analysis. Man (N.S), 15(1):151-169.

1989. Morgan vs. Dorsey on the Omaha cross/parallel contrast: Theoretical implications. L'Homme 29(1):76-106.

1995. Kinship as distributed cognition. Paper delivered at the $94^{\text {th }}$ AAA Annual Meeting.

2001. Morgan, Trautmann and Barnes, and the Iroquois-Type cross/parallel distinction. Anthropos 96:423-432.

LAWRENCE, W.E. 1969 [1937]. Alternating generations in Australia. In Studies in the science of socictp. Edited by G.D. Murdock. pp. 319-354. Freeport, New York: Books for Library Press.

LEACH, EDMUND R. 1965. Unilateral cross-cousin marriage. Man 65(11-114):25, article 12.

LONG, RICHARD C.E. 1916. Some Australian classes, named and nameless. Man 16:165-8.

LOUNSBURY, F.G. 1956. A Semantic analysis of the Pawnee kinship usige. Language 32(1): 158-194.

1964. The structural analysis of kinship semantics. In Proceedings of the nimth imternational congress of linguistics. Edited by H.G. Lunt, pp. 1073-90. The Hague: Mouton.

MALINOWSKI. B. 1929. The sexial life of savages. New York: Harcourt. Brace \& World.

MCCONVELL, P, and B. ALPHER. 2002. On the Omaha trail in Australia: Tracking skewing from east to west. Anthropological Fortum 12(2):159-175.

MCCONVELL, P. 1985. The origin of subsections in northern Australia. Oceania 56(1):1-33

1996. Backtracking to Babel: The chronology of Pama-Nyungan expansion in Australia. Archaeology in Oceania 31 (3): 125-44.

McKELLIN, W.H. 1995. Cognition, meaning and kinship: Connectionist models of cultural representation. Culhure 15(1):19-31. 
NEEDHAM. R. 1973. Prescriplion. Oceania 43(3):166-81.

NORICKS, J.S. 1987. Testing for cognitive validity: Componential analysis and the question of extensions (research report). American Anthropologist 89(2):424-438.

POWELL, F. 2002. Transformations in Guugu Yimithirr kinship terminology. Anlhropological Fortum 12(2):177192.

RADCLIFFE-BROWN, A.R. 1913. Three tribes of Western Australia. Joumal of the Royal Amhropological Institute of Great Britain and lireland 43:143-194.

1930-31. The social organization of Australian tribes. Oceania 1(1-4):34-63, 206-46, 322-41, 426-56.

1953. Dravidian kinship terminology. Man 53(112):112.

SCHEFFLER, H.W. 1971. Some aspects of Australian kin classification: A correction. Mankind 8(1):25-30.

1972. Systems of kin classification: A structural typology. In Kinship studies in the Morgan centenuinl year. Edited by P. Reining, pp. 113-133. Washington: The Anthropological Society of Washington.

1978. Australian kin classification. Cambridge: Cambridge University Press, Cambridge Studies in Social Anthropology, 33

1987. Markedness in systems of kin classification, Journal of Anthropological Research, 43(3): 203-221.

SCHNEIDER, D.M. 1965. American kin terms and terms for kinsmen: A critique of Goodenough's componential analysis of Yankee kinship terminology. American Anthropologist 67(5):288-316.

SERVICE, E.R. 1960. Sociocentric relationship terms and the Australian class system. In Essays in the science of culture in honour of Leslie G. White. Edited by G.E. Dole \& R.L. Carneiro, pp. 416-36. New York: Thomas Crowell.

SHAPIRO, W. 1970. The ethnography of two-section systems. Ethnology 9(4):380-8.

STREHLOW, T.G.H. 1999. Aranda regular and irregular marriages. Strehlow Research Centre Occasional Papers 2:1-43.

SUTTON, P. 1998. Native Title and the descent of rights. Perth: Native Title Tribunal.

TESTART, A. 1985. Le communisme primitif: Economie et idéologie. Paris: Maison des Sciences de l'Homme.

1995. Age et génération chez les Aborigènes australiens. L'Homme 134:171-178.

TONKINSON, R. 199 [ [1978]. The Mardu Aborigines: Living the Dream in Australia's desert. New York: Holt, Rinehart \& Winston, Case Studies in cultural Anthropology.

n.d.. The riddle of the non-marriageable cross-cousin. Unpublished seminar given at the National University of Australia, Canberra, 1975 .

TRAUTMANN, THOMAS R., AND R.H. BARNES. 1998. 'Dravidian', 'Iroquois', and 'Crow-Omaha' in North American perspective. In Transformations of kinship. Edited by M. Godelier, T.R. Trautmann \& F.E. Tjon Sie Fat, pp. 27-58. Washington \& London: Smithsonian Institution.

VIVEIROS DE CASTRO, E. 1998. Dravidian and related kinship systems. In Transformations of kinship. Edited by M. Godelier, T.R. Trautmann \& F.E. Tjon Sie Fat (eds), pp. 332-385. Washington \& London: Smithsonian Institution.

VON STURMER, J. 1981. Talking with Aborigines. Australian Institute of Aboriginal Studies Newsletter, 15: 1330 .

WAUGH, L. 1982. Marked and unmarked: A choice between unequals in semiotic structure. Semiotica, 18: 299 . 318. 